\title{
Medication-related problems among hospitalized pregnant women in a tertiary teaching hospital in Ethiopia: a prospective observational study
}

\author{
Seid Mussa Ahmed ${ }^{1,2^{*}}$ (D) Johanne Sundby ${ }^{1}$, Yesuf Ahmed Aragaw $^{3}$ and Hedvig Nordeng ${ }^{4,5}$
}

\begin{abstract}
Background: Studies on medication-related problems (MRPs) among pregnant women are scarce, despite the potential consequences for both mother and child. This study aimed to describe the prevalence, clinical significance, and risk factors for MRPs among hospitalized pregnant or postpartum women at Jimma University Medical Centre (JUMC) in Ethiopia.

Methods: A prospective follow-up and clinical audit of 1117 hospitalized pregnant or postpartum women in the maternity and gynaecology wards at JUMC was carried out between February and June 2017. Patients were followed throughout their stay in the hospital to assess the presence and development of MRPs. Pre-tested data extraction form and an interview-guided structured questionnaire were used to collect data. Descriptive statistics were used to describe MRPs. Logistic regression analysis was used to identify factors associated with MRPs.

Results: One or more MRPs occurred among 323 (28.9\%) study participants, mostly in relation to lack of iron supplementation. A total of $278(70.6 \%)$ of all MRPs were considered to be of moderate to high clinical significance. When excluding MRPs due to iron from the analysis, chronic disease (adjusted OR 1.91; 95\% Cl 1.02, 3.58), medication use prior to admission (adjusted OR 2.38; 95\% Cl 1.24, 4.56), nulliparity (adjusted OR 1.99; 95\% Cl 1.22, 3.24) and multiparity (adjusted OR 1.91; $95 \% \mathrm{Cl} 1.17,3.12$ ) were significantly associated with experiencing an MRP.

Conclusions: Nearly 3 out of 10 hospitalized pregnant women at JUMC had one or more MRPs. The need for additional iron therapy was by far the most common type of MRP. Improved adherence to guidelines on iron supplementation are required. Multidisciplinary approaches including physicians, nurses, anesthesia professionals and clinical pharmacists in the maternity and gynaecology wards could possibly prevent MRPs and promote patient safety for women and children.
\end{abstract}

Keywords: Medication-related problem, Maternity, Gynaecology, Pregnancy, Clinical significance, Iron supplementation

\footnotetext{
* Correspondence: seidma@studmed.uio.no

'Department of Community Medicine and Global Health, Institute of Health and Society, Faculty of Medicine, University of Oslo, Oslo, Norway

2Division of Social and Administrative Pharmacy, School of Pharmacy, Faculty

of Health Sciences, Jimma Institute of Health, Jimma University, Jimma,

Ethiopia

Full list of author information is available at the end of the article
}

(c) The Author(s). 2020 Open Access This article is licensed under a Creative Commons Attribution 4.0 International License, which permits use, sharing, adaptation, distribution and reproduction in any medium or format, as long as you give appropriate credit to the original author(s) and the source, provide a link to the Creative Commons licence, and indicate if changes were made. The images or other third party material in this article are included in the article's Creative Commons licence, unless indicated otherwise in a credit line to the material. If material is not included in the article's Creative Commons licence and your intended use is not permitted by statutory regulation or exceeds the permitted use, you will need to obtain permission directly from the copyright holder. To view a copy of this licence, visit http://creativecommons.org/licenses/by/4.0/ The Creative Commons Public Domain Dedication waiver (http://creativecommons.org/publicdomain/zero/1.0/) applies to the data made available in this article, unless otherwise stated in a credit line to the data. 


\section{Background}

A medication-related problem (MRP) is defined as an unwanted event or circumstance involving medication therapy that actually or potentially interferes with desired health outcomes [1, 2]. Studies have shown that the prevalence of MRPs among hospitalized pregnant patients varies from 42 to $83 \%$ [3, 4]. Patients who have MRPs are likely to have a longer hospital stay, recurrent hospital admissions, reduced quality of life, increased overall health care cost, and even an increased risk of morbidity and mortality [4-6].

Only a handful of studies have examined the frequency and nature of MRPs occurring in an obstetric hospital inpatient setting $[3,4]$. A recently published Norwegian study of 212 pregnant women in an inpatient setting identified 105 MRPs occurring in $42 \%$ of pregnant women. "Need for additional drug" (46.7\%), "adverse drug reaction" (20.0\%), and "patient adherence" (10.5\%) were the most common categories of MRPs. The most common medication groups involved in the MRPs were drugs acting on the respiratory system (25\%; mainly nasal decongestants, 9\%), anti-infectives for systemic use (18\%; mainly antibiotics for systemic use, $8 \%$ ), and drugs acting on blood and blood-forming organs (16\%; mainly iron supplementation, 14\%) [4]. A study from Australia identified 400 potential MRPs in 171 of 205 hospitalized pregnant women. The majority of MRPs were of low clinical significance (92\%). The most common types of MRPs were "incomplete medications charted on admission" (28\%), "dose too high" (26\%), "incomplete drug order" (15\%), and "additional medication required" (13\%). The therapeutic groups most commonly associated with MRPs were medications for the alimentary tract and metabolism, mainly aperients $(18 \%)$ and vitamins (13\%), followed by drugs for the nervous system, mainly analgesics $(25 \%)$ and antidepressants (4\%) [3]. In addition to these two studies, a few studies have evaluated medication errors in obstetric and maternity wards [7-9].

In Ethiopia, previous studies have focused mainly on prescription drug use, drug use patterns, and selfmedication practices among pregnant outpatients attending obstetrics and gynaecology departments [10-13]. Notably, none of these prior investigations involved the identification of MRPs and were conducted in ambulatory pregnant patients. Although few MRPs identification studies were performed among hospitalized patients in the country, all focused on the non-pregnant patient population [14-17]. Thus far, no study has investigated MRPs in an obstetrics group in a hospital setting in Ethiopia. Therefore, the objective of the present study was to determine the prevalence, clinical significance, and risk factors of MRPs occurring in hospitalized pregnant women in the maternity and gynaecology wards of Jimma University Medical Centre (JUMC) in Southwest Ethiopia.

\section{Methods}

\section{Sample size}

The required sample size for this study was calculated assuming a $50 \%$ proportion of MRPs, $5 \%$ level of precision, 3\% error margin, and 5\% possible non-response rate, making the minimum sample size 1121 pregnant women.

\section{Study setting}

A facility-based prospective observational study was conducted in the maternity and gynaecology wards of JUMC, a tertiary level public teaching hospital located in Jimma City in southwest Ethiopia, $350 \mathrm{~km}$ from the capital city of Addis Ababa. It is the only teaching and tertiary level care hospital in southwest Ethiopia, with a catchment population of approximately 20 million people $[18,19]$. Most of the pregnant women referred to the hospital come from rural areas, where many deliveries are attended at home $[20,21]$. The Department of Obstetrics and Gynaecology at JUMC provides specialized health services for approximately 7580 inpatients and 11,590 outpatients each year, with a bed capacity of 265. The department has two wards (gynaecology and maternity/labour), one general gynaecological outpatient clinic, one antenatal care outpatient clinic, and one family planning clinic. Women are treated at the gynaecology inpatient ward before 28 weeks of pregnancy. Most pregnant women admitted to this ward have elective and/or spontaneous abortions, hyperemesis gravidarum (HEG), or other early pregnancy complications. After 28 weeks of pregnancy, women are admitted to the maternity/labour inpatient ward. Women having a vaginal delivery give birth in the labour ward and are transferred to the maternity ward after delivery. If the mother and baby are healthy, they are discharged at the earliest possible time after delivery, usually within 1-2 days. Women having a caesarean delivery are transferred to the maternity ward and usually stay for $72 \mathrm{~h}$.

\section{Data collection and procedures}

Women in the maternity and gynaecology wards at JUMC between February and June 2017 were invited to participate in the study during normal working hours. Patients were informed of the aim and procedures of the study, and written informed consent was obtained from each study participant. Women who were under 18 years of age, too ill to participate, who declined to participate, were hard of hearing, unable to speak or with mental illness, admitted for a brief time $(<4 \mathrm{~h})$, and non-pregnant women admitted to the gynaecology ward were excluded from the study.

The women were followed throughout their stay in the hospital to assess the presence and development of MRPs. Pre-tested data extraction form and an interview- 
guided structured questionnaire were used to collect the data. Five trained clinical pharmacists (data abstraction and MRP assessment) and four trained nurses (the questionnaire) from JUMC collected the data.

Information on the reason for admission, diagnoses, dosage regimens, discharge medications, maternal and perinatal outcomes, laboratory results, and length of hospital stay was collected by reviewing patients' medical cards and medication charts. The card and chart reviews were performed for each patient on the first day of admission and repeated on subsequent days. The questionnaire was used to collect maternal socio-demographic characteristics, obstetric history, past medical history and medication experience, social drug use, and medicinal plant use.

\section{MRP identification and assessment}

MRPs were classified into eight categories: need for additional drug therapy, unnecessary drug therapy, dose too low, dose too high, ineffective drug, adverse drug reactions, noncompliance [1], and other, subdivided into need for additional laboratory test and/or incomplete drug order (Additional file 1) [3].

MRPs were identified by reviewing patients' medical cards and medication charts, and patient interviews about medication use while in the hospital. A panel of experts comprised of senior clinical pharmacists and experienced obstetricians/gynaecologists identified MRPs and classified them into categories as recommended by Cipolle et al. [1] The panel of experts further refined the MRP identification and classification method for the study setting in accordance with Ethiopian standard treatment guidelines and literature reviews (Additional file 1) [3, 22-25].

The clinical significance of each MRP was categorized as level 1 or level 2 [3]. Level 1 are those MRPs that have low potential to give rise to patient discomfort or clinical deterioration whereas level 2 are MRPs that have moderate to severe potential to give rise to patient discomfort or clinical deterioration [3, 26]. At first, experienced clinical pharmacists identifying MRPs in the wards assessed and classified the clinical significance, and subsequently discussed by the panel of experts. Differences in opinion on severity level of MRPs were discussed until consensus was reached. The description of the MRPs, their clinical significance, and the medication (s) involved were recorded using a purpose-built data collection tool.

The classification of medications involved in MRPs was performed per the World Health Organization (WHO) Anatomical Therapeutic Chemical Classification system (ATC) that categorizes medications into 14 main groups [27].

\section{Statistical analysis}

Descriptive statistics were used to calculate percentages. The results were presented as medians and ranges. Univariate and multivariate logistic regression analyses were used to calculate odds ratios (ORs) with 95\% confidence intervals (CIs) and identify risk factors associated with MRPs. The independent variables were patient-related factors (age, level of education, marital status, occupation, religion, ethnic group, family size, residence place, alcohol use status, and khat chewing), disease-related factors (patient admission ward, i.e., gynaecology or maternity ward; chronic disease; obstetrics category, i.e., caesarean or vaginal delivery; duration of hospital stay), pregnancy related factors (parity, gravidity, gestational age, adverse pregnancy outcome [current and previous], status of anaemia), medicine-related factors (medicines used during admission or prior to admission, ferrous sulphate supplementation, medicinal plant use, concomitant use of medicinal plants), facility-related factors (walking distance to the nearest health facility, and availability of preferred medication for a specific condition). Explanatory variables with $p \leq 0.05$ in the univariate analysis were entered into a multivariate logistic regression model to determine independent risk factors of MRPs. As iron supplements were involved in 165 (41.9\%) of the MRPs, a post hoc logistic regression analysis was performed excluding iron. All data were analysed using the Statistical Package for the Social Sciences (SPSS) software version 25.0 for Windows (IBM ${ }^{\circ}$ SPSS $^{\circ}$ Statistics, Armonk).

\section{Results}

\section{Study population characteristics}

A total of 1137 pregnant and nursing women were asked to participate in the study, and 1121 (98.6\%) accepted. Responses from four women were incomplete, leaving 1117 women in the final study population, $88.8 \%$ from the maternity ward (611 vaginal deliveries, 372 caesarean sections, and 9 did not proceed to parturition) and 11.2\% from the gynaecology ward. The median patient age was 25 years (range 18-45 years). Most of the women were either primiparous or multiparous (40\% each). Most women gave birth at term (65.8\%) through vaginal labour (54.7\%). Five percent of the women had one or more chronic diseases. The median length of hospital stay was 3 days, ranging from $5 \mathrm{~h}$ to 60 days, and most of the patients (59.7\%) stayed $\leq 3$ days in the hospital. A fifth of the women (19.4\%) had adverse pregnancy outcomes in the current pregnancy, and 1 in 10 women (11.0\%) had a history of adverse pregnancy outcomes. Detailed sociodemographic characteristics and clinical data are summarized in Tables 1 and 2. In this study, concomitant use of phytomedicines and conventional medicines was assessed by identifying women who used both during pregnancy for the same or different illnesses.

\section{Medicine use during pregnancy and admission}

The majority of the women had used one or more medications during pregnancy (85.2\%), whereas $28.6 \%$ of 
Table 1 Risk factors of medication-related problems ${ }^{\text {a }}$

\begin{tabular}{|c|c|c|c|c|c|}
\hline \multirow[t]{2}{*}{ Characteristics } & \multirow{2}{*}{$\begin{array}{l}\text { No. (\%) } \\
1117 \text { (100) }\end{array}$} & \multicolumn{2}{|l|}{ MRPs } & \multirow{2}{*}{$\begin{array}{l}\text { Crude OR } \\
(95 \% \mathrm{Cl})\end{array}$} & \multirow{2}{*}{$\begin{array}{l}\text { Adjusted OR } \\
(95 \% \mathrm{Cl})^{\mathbf{b}}\end{array}$} \\
\hline & & No MRPs & $\geq 1 \mathrm{MRP}$ & & \\
\hline \multicolumn{6}{|l|}{ Age (years) } \\
\hline$\leq 20$ & $223(20.0)$ & 169 & 54 & 1 & 1 \\
\hline $21-25$ & $388(34.7)$ & 278 & 110 & $1.24[0.85,1.81]$ & $1.34[0.91,1.98]$ \\
\hline $26-30$ & $320(28.7)$ & 216 & 104 & $1.51[1.03,2.22]$ & $1.63[1.07,2.50]$ \\
\hline$\geq 31$ & $186(16.7)$ & 131 & 55 & $1.31[0.85,2.04]$ & $1.31[0.79,2.19]$ \\
\hline \multicolumn{6}{|l|}{ Residence place } \\
\hline Urban & $595(53.3)$ & 423 & 172 & 1 & \\
\hline Rural & $522(46.7)$ & 371 & 151 & $1.00[0.77,1.30]$ & \\
\hline \multicolumn{6}{|l|}{ Chronic disease } \\
\hline Yes & $56(5.0)$ & 34 & 22 & 1 & \\
\hline No & $1061(95.0)$ & 760 & 301 & $0.61[0.35,1.06]$ & \\
\hline \multicolumn{6}{|l|}{ Medicinal plant used in current pregnancy } \\
\hline Yes & $319(28.6 \%)$ & 228 & 91 & 1 & \\
\hline No & $798(71.4 \%)$ & 566 & 232 & $1.03[0.77,1.37]$ & \\
\hline \multicolumn{6}{|l|}{ Alcohol consumers } \\
\hline Yes & $46(4.1)$ & 33 & 13 & 1 & \\
\hline No & $1071(95.9)$ & 761 & 310 & $1.03[0.54,1.99]$ & \\
\hline \multicolumn{6}{|l|}{ Khat chewers ${ }^{c}$} \\
\hline Yes & $65(5.8)$ & 44 & 21 & 1 & \\
\hline No & $1052(94.2)$ & 750 & 302 & $0.84[0.49,1.44]$ & \\
\hline \multicolumn{6}{|l|}{ No. of medicines during admission } \\
\hline$<5$ medication & $631(57.3)$ & 455 & 176 & 1 & \\
\hline$\geq 5$ medication & $470(42.7)$ & 329 & 141 & $1.11[0.85,1.44]$ & \\
\hline \multicolumn{6}{|l|}{ No. of medicines prior to admission } \\
\hline No past medication & $165(14.8)$ & 119 & 46 & 1 & \\
\hline Only one past medication & $666(59.6)$ & 466 & 200 & $1.11[0.76,1.62]$ & \\
\hline Two or more past medications & $286(25.6)$ & 209 & 77 & $0.95[0.62,1.46]$ & \\
\hline \multicolumn{6}{|l|}{ Duration of hospital stay } \\
\hline$\leq 3$ days & $667(59.7)$ & 482 & 185 & 1 & \\
\hline$>3$ days & $450(40.3)$ & 312 & 138 & $1.15[0.89,1.50]$ & \\
\hline \multicolumn{6}{|l|}{ Gestational age } \\
\hline Preterm pregnancy & $231(20.7)$ & 150 & 81 & 1 & 1 \\
\hline Term pregnancy & $735(65.8)$ & 539 & 196 & $0.67[0.49,0.92]$ & $0.79[0.51,1.23]$ \\
\hline Post term pregnancy & $62(5.6)$ & 46 & 16 & $0.64[0.34,1.21]$ & $0.72[0.36,1.46]$ \\
\hline Others & $89(8.0)$ & 59 & 30 & $0.94[0.56,1.58]$ & $1.04[0.58,1.89]$ \\
\hline \multicolumn{6}{|l|}{ Patient ward } \\
\hline Gynaecology ward & $125(11.2)$ & 78 & 47 & 1 & 1 \\
\hline Maternity ward & $992(88.8)$ & 716 & 276 & $0.64[0.43,0.94]$ & $0.76[0.44,1.30]$ \\
\hline \multicolumn{6}{|l|}{ Adverse pregnancy outcome in the current pregnancy } \\
\hline Yes & $217(19.4)$ & 149 & 68 & 1 & \\
\hline No or not yet delivered and outcome not yet known & $900(80.6)$ & 645 & 255 & $0.87[0.63,1.20]$ & \\
\hline \multicolumn{6}{|l|}{ Previous adverse pregnancy outcome } \\
\hline Yes & $123(11.0)$ & 84 & 39 & 1 & \\
\hline
\end{tabular}


Table 1 Risk factors of medication-related problems ${ }^{a}$ (Continued)

\begin{tabular}{|c|c|c|c|c|c|}
\hline \multirow[t]{2}{*}{ Characteristics } & \multirow{2}{*}{$\begin{array}{l}\text { No. (\%) } \\
1117(100)\end{array}$} & \multicolumn{2}{|l|}{ MRPs } & \multirow{2}{*}{$\begin{array}{l}\text { Crude OR } \\
(95 \% \mathrm{Cl})\end{array}$} & \multirow{2}{*}{$\begin{array}{l}\text { Adjusted OR } \\
(95 \% \mathrm{Cl}){ }^{\mathrm{b}}\end{array}$} \\
\hline & & No MRPs & $\geq 1 \mathrm{MRP}$ & & \\
\hline No/not Applicable & $994(89.0)$ & 710 & 284 & $0.86[0.58,1.29]$ & \\
\hline \multicolumn{6}{|l|}{ Parity } \\
\hline Primiparous & $227(20.3)$ & 181 & 46 & 1 & 1 \\
\hline Nulliparous & 441 (39.5) & 308 & 133 & $1.70[1.16,2.49]$ & $1.82[1.23,2.69]$ \\
\hline Multiparous & 449 (40.2) & 305 & 144 & $1.86[1.27,2.72]$ & $1.73[1.16,2.59]$ \\
\hline
\end{tabular}

Bold, statistically significant, $P<0.05$

a Numbers may not add up to $100 \%$ due to missing values

${ }^{\mathrm{b}}$ Adjusted for age, gestational age, patient ward and parity

c Khat (Catha edulis) plant leaves are chewed by people to attain a state of euphoria and stimulation

women (Tables 1 and 2) had used medicinal plants. Ferrous sulphate was the most commonly used medication prior to hospital admission (97.3\%). Furthermore, 271 (24.3\%) women concomitantly used medicinal plants and medicines prior to admission.

During admission, the median number of prescribed medications was 3 per patient (range: 0-24; Additional file 2) and $42.7 \%$ of the participants were taking $\geq 5$ medications (Tables 1 and 2). The three most common types of medications given during the women's hospital stay were pitocin (63.7\%), normal saline (38.9\%), and ceftriaxone $(36.0 \%)$ (Additional file 3). Ferrous sulphate $(54.4 \%)$, cephalexin $(30.4 \%)$, and metronidazole (25.0\%) were the three most common medications prescribed at hospital discharge (Additional file 4).

\section{Medication use-related problems}

One or more MRPs occurred among 28.9\% of the study participants: $23.7 \%$ had one MRP, $4.2 \%$ had two MRPs, $0.8 \%$ had three MRPs, and $0.2 \%$ had four MRPs. A total of 394 discrete MRPs were noted. The highest number of MRPs, $87.6 \%$, was identified among women admitted in the maternity ward (228 MRPs among those with vaginal delivery, 114 MRPs among caesarean sections, and 3 among those not yet delivered; Table 1, Additional file 2).

Two hundred and seventy-eight (70.6\%) of all MRPs were considered to be of moderate to high clinical significance and classified as level 2 MRPs. One hundred sixty five (41.9\%) of the total MRPs (133 (47.8\%) of level 2 and $32(39.0 \%)$ of level 1 MRPs) were due to iron treatment/supplementation.

Chart reviews were usually performed twice, with a range of one to three reviews (Additional file 2).

In $14.5 \%$ of patients, lack of chart recording or documentation of medication administration occurred, most commonly for ceftriaxone, anaesthetic drugs, and intravenous fluids in relation to caesarean section in the surgical delivery room. The assessment panel of experts agreed not to consider this an MRP, as the medications were appropriately administered to the patients.
The types of MRPs according to the eight main MRP categories are presented in Table 3. The most common MRP types were: need for additional drug therapy $(n=$ 236 cases, $73.1 \%$ ), need for an additional laboratory test ( $n=41$ cases, $12.7 \%)$, unnecessary drug therapy $(n=38$ cases, $11.8 \%)$, and too low dosage $(n=38$ cases, $11.8 \%$; Table 3).

A more detailed overview of the specific causes of MRPs and medications involved in MRPs are found in Additional file 5 and Additional file 6, respectively.

As indicated in Fig. 1, the most common therapeutic group implicated in MRPs were medications acting on blood and blood-forming organs, mainly ferrous sulphate (35.3\%), followed by anti-infectives for systemic use, largely cephalexin and metronidazole (each 9.4\%).

\section{Factors contributing to MRPs}

Nulliparous (adjusted OR 1.82; 95\% CI 1.23, 2.69) and multiparous (adjusted OR 1.73; 95\% CI 1.16, 2.59) women were significantly more likely to experience MRP than primiparous women. Similarly, women aged $>26$ years (adjusted OR 1.63; 95\% CI 1.07, 2.50) were more likely to experience MRPs than their counterparts (Table 1). However, in a post hoc analysis excluding MRPs due to iron from the analysis, only parity was maintained as a risk factor. Additional risk factors, including chronic disease (adjusted OR 1.91; 95\% CI 1.02, 3.58) and past medication use (adjusted OR 2.38; 95\% CI 1.24, 4.56; adjusted OR 2.21; $95 \%$ CI 1.12, 4.38) were associated with a significantly increased likelihood of experiencing an MRP than their counterparts (Table 2).

All MRPs were considered clinically significant for the patients. Most commonly, "need for additional medication therapy" included untreated disease conditions, mainly anaemia or an absence of anti-infection prophylaxis, as in patients at risk of infection due to retained placenta not receiving prophylactic antibiotic. Additional file 5 describes in detail the different types and causes of MRPs. 
Table 2 Risk factors of medication-related problems, excluding iron preparations ${ }^{\text {a }}$

\begin{tabular}{|c|c|c|c|c|c|}
\hline \multirow[t]{2}{*}{ Variable category } & \multirow{2}{*}{$\begin{array}{l}\text { No. (\%) } \\
1117(100)\end{array}$} & \multicolumn{2}{|c|}{ Non-Iron MRPs ${ }^{b}$} & \multirow{2}{*}{$\begin{array}{l}\text { Crude OR } \\
(95 \% \mathrm{Cl})\end{array}$} & \multirow{2}{*}{$\begin{array}{l}\text { Adjusted OR } \\
(95 \% \mathrm{Cl})^{c}\end{array}$} \\
\hline & & No MRPs & $\geq 1 \mathrm{MRP}$ & & \\
\hline \multicolumn{6}{|l|}{ Age } \\
\hline$\leq 20$ & $223(20.0)$ & 190 & 33 & 1 & \\
\hline $21-25$ & $388(34.7)$ & 325 & 63 & $1.12[0.71,1.76]$ & \\
\hline $26-30$ & $320(28.7)$ & 259 & 61 & $1.36[0.85,2.16]$ & \\
\hline$\geq 31$ & $186(16.7)$ & 159 & 27 & $0.98[0.56,1.70]$ & \\
\hline \multicolumn{6}{|l|}{ Residence place } \\
\hline Urban & $595(53.3)$ & 493 & 102 & 1 & \\
\hline Rural & $522(46.7)$ & 440 & 82 & $0.90[0.66,1.24]$ & \\
\hline \multicolumn{6}{|l|}{ Chronic disease } \\
\hline No & $1061(95.0)$ & 892 & 169 & 1 & 1 \\
\hline Yes & $56(5.0)$ & 41 & 15 & $1.93[1.05,3.57]$ & $1.91[1.02,3.58]$ \\
\hline \multicolumn{6}{|l|}{ Medicinal plant used in current pregnancy } \\
\hline Yes & $319(28.6 \%)$ & 265 & 54 & 1 & \\
\hline No & $798(71.4 \%)$ & 668 & 130 & $0.96[0.68,1.35]$ & \\
\hline \multicolumn{6}{|l|}{ Alcohol consumers } \\
\hline Yes & $46(4.1)$ & 37 & 9 & 1 & \\
\hline No & $1071(95.9)$ & 896 & 175 & $0.80[0.38,1.69]$ & \\
\hline \multicolumn{6}{|l|}{ Khat chewers ${ }^{d}$} \\
\hline Yes & $65(5.8)$ & 59 & 6 & 1 & \\
\hline No & $1052(94.2)$ & 874 & 178 & $2.00[0.85,4.71]$ & \\
\hline \multicolumn{6}{|l|}{ No. of medicines during admission } \\
\hline$<5$ medication & $631(57.3)$ & 520 & 111 & 1 & \\
\hline$\geq 5$ medication & $470(42.7)$ & 399 & 71 & $0.83[0.60,1.15]$ & \\
\hline \multicolumn{6}{|l|}{ No. of medicines prior to admission } \\
\hline No past medication & $165(14.8)$ & 152 & 13 & 1 & 1 \\
\hline Only one past medication & $666(59.6)$ & 546 & 120 & $2.57[1.41,4.68]$ & $2.38[1.24,4.56]$ \\
\hline Two or more past medications & $286(25.6)$ & 235 & 51 & $2.54[1.34,4.82]$ & $2.21[1.12,4.38]$ \\
\hline \multicolumn{6}{|l|}{ Duration of hospital stay } \\
\hline$\leq 3$ days & $667(59.7)$ & 555 & 112 & 1 & \\
\hline$>3$ days & $450(40.3)$ & 378 & 72 & $0.94[0.68,1.31]$ & \\
\hline \multicolumn{6}{|l|}{ Gestational age } \\
\hline Preterm pregnancy & $231(20.7)$ & 199 & 32 & 1 & \\
\hline Term pregnancy & $735(65.8)$ & 608 & 127 & $1.30[0.85,1.98]$ & \\
\hline Post term pregnancy & $62(5.6)$ & 51 & 11 & $1.34[0.63,2.84]$ & \\
\hline Others & $89(8.0)$ & 75 & 14 & $1.16[0.59,2.30]$ & \\
\hline \multicolumn{6}{|l|}{ Patient ward } \\
\hline Gynaecology ward & $125(11.2)$ & 113 & 12 & 1 & 1 \\
\hline Maternity ward & $992(88.8)$ & 820 & 172 & $1.98[1.07,3.66]$ & $1.34[0.68,3.58]$ \\
\hline \multicolumn{6}{|l|}{ Adverse pregnancy outcome in the current pregnancy } \\
\hline Yes & $217(19.4)$ & 185 & 32 & 1 & \\
\hline No or not yet delivered and outcome not yet known & $900(80.6)$ & 748 & 152 & $1.18[0.78,1.78]$ & \\
\hline \multicolumn{6}{|l|}{ Previous adverse pregnancy outcome } \\
\hline Yes & $123(11.0)$ & 106 & 17 & 1 & \\
\hline
\end{tabular}


Table 2 Risk factors of medication-related problems, excluding iron preparations ${ }^{a}$ (Continued)

\begin{tabular}{|c|c|c|c|c|c|}
\hline \multirow[t]{2}{*}{ Variable category } & \multirow{2}{*}{$\begin{array}{l}\text { No. (\%) } \\
1117 \text { (100) }\end{array}$} & \multicolumn{2}{|c|}{ Non-Iron MRPs ${ }^{b}$} & \multirow{2}{*}{$\begin{array}{l}\text { Crude OR } \\
(95 \% \mathrm{Cl})\end{array}$} & \multirow{2}{*}{$\begin{array}{l}\text { Adjusted OR } \\
(95 \% \mathrm{Cl})^{c}\end{array}$} \\
\hline & & No MRPs & $\geq 1 \mathrm{MRP}$ & & \\
\hline No/not Applicable & 994 (89.0) & 827 & 167 & $1.26[0.74,2.16]$ & \\
\hline \multicolumn{6}{|l|}{ Parity } \\
\hline Primiparous & $227(20.3)$ & 203 & 24 & 1 & 1 \\
\hline Nulliparous & $441(39.5)$ & 360 & 81 & $1.90[1.17,3.10]$ & $1.99[1.22,3.24]$ \\
\hline Multiparous & $449(40.2)$ & 370 & 79 & $1.81[1.11,3.94]$ & $1.91[1.17,3.12]$ \\
\hline
\end{tabular}

Bold, statistically significant, $P<0.05$

Abbreviations: OR: odd ratio; $\mathrm{Cl}$ : Confidence interval

a Numbers may not add up to $100 \%$ due to missing values

${ }^{\mathrm{b}}$ No MRPs $=$ MRPs due to other medications + Patients with No MRPs. $\geq 1$ MRP $=\geq 1$ MRPs due to iron sulphate

${ }^{c}$ Adjusted for chronic disease, number of medicines prior to admission, patient ward and parity

${ }^{d}$ Khat (Catha edulis) plant leaves are chewed by people to attain a state of euphoria and stimulation

\section{Discussion}

This study provides new knowledge about the prevalence, clinical significance, risk factors, and medications implicated in MRPs among hospitalized pregnant women in a resource-limited setting. To the best of our knowledge, this is the first study in Ethiopia to investigate the extent of MRPs in hospitalized pregnant women. Approximately 3 out of 10 pregnant women had one or more MRPs, mostly in relation to a lack of iron supplementation. More than 7 out of 10 MRPs were considered to be of moderate to severe clinical relevance. This high magnitude and the frequency of these MRPs suggests problems inherent in the day-to-day practices of the study wards. These problems can potentially be improved through internal audits, improved routines, and systemic changes, including multidisciplinary collaboration, training, and increased staff.

In the present study, nearly one-third of pregnant and nursing women encountered at least one MRP. This is lower than reported in studies of Norwegian [4] and Australian [3] pregnant and lactating inpatients, as 42.0 and $83.4 \%$ of the study participants, respectively, experienced at least one MRP. This large variation in prevalence is likely a reflection of the methodological differences between the studies, especially the process of medication reconciliation and medication chart reviews.

Table 3 Overview of Medication Related Problems (MRP) according to frequency and types

\begin{tabular}{|c|c|c|c|}
\hline MRPs Category & Type of MRP & $n(\%)^{a}$ & Example \\
\hline \multirow[t]{2}{*}{ Indication } & Needs additional drug therapy & $236(73.1)$ & $\begin{array}{l}\text { Patient is asthmatic, but is not getting the recommended drug } \\
\text { i.e. salbutamol puff PRN }\end{array}$ \\
\hline & Unnecessary drug therapy & $38(11.8)$ & $\begin{array}{l}\text { Patient is on ceftriaxone } 1 \mathrm{~g} \mathrm{IV} \mathrm{BID} \mathrm{but} \mathrm{there} \mathrm{is} \mathrm{no} \mathrm{indication} \\
\text { of infection in the diagnosis }\end{array}$ \\
\hline \multirow[t]{2}{*}{ Effectivenes } & Dosage too low & $38(11.8)$ & $\begin{array}{l}\text { Cephalexin } 500 \text { mg once PO daily given to patient to treat infection, } \\
\text { PO BID daily is recommended }\end{array}$ \\
\hline & Ineffective drug product & $12(3.7)$ & $\begin{array}{l}\text { HIV/AIDS (immunocompromised) and MRSA infected patient who } \\
\text { was on wound care was on metronidazole and cephalexin treatment } \\
\text { (less effective), instead patient was put on more effective drug, } \\
\text { vancomycin } 500 \text { mg IV BID for } 10 \text { days }\end{array}$ \\
\hline \multirow[t]{2}{*}{ Safety } & Dosage too high & $12(3.7)$ & $\begin{array}{l}\text { Patient is on ceftriaxone } 2 \mathrm{~g} \mathrm{IV} \text { bid to treat chorioamnionitis which } \\
\text { is high dose, } 1 \mathrm{~g} \mathrm{IV} \mathrm{BID} \mathrm{is} \mathrm{enough}\end{array}$ \\
\hline & Adverse drug reaction & $2(0.6)$ & $\begin{array}{l}\text { Patient received furosemide and gentamicin concurrently. One increases } \\
\text { toxicity of the other by pharmacodynamic synergism; alternative drug } \\
\text { chlorothiazide was used in place of furosemide }\end{array}$ \\
\hline Compliance & Non-compliance & $12(3.7)$ & $\begin{array}{l}\text { Anti-D immunoglobulin is available in the hospital, but the patient } \\
\text { couldn't afford and was not injected }\end{array}$ \\
\hline \multirow[t]{2}{*}{ Other categories } & $\begin{array}{l}\text { Need for an additional } \\
\text { laboratory test }\end{array}$ & $41(12.7)$ & $\begin{array}{l}\text { Patient haematocrit value is not registered to recommend or not iron } \\
\text { supplementation or treatment }\end{array}$ \\
\hline & Incomplete drug order & $3(0.9)$ & $\begin{array}{l}\text { Patient is prescribed with methyldopa } 250 \mathrm{mg} \text { (mild pre-eclampsia), } \\
\text { but duration was not indicated }\end{array}$ \\
\hline Total MRPs & & $394(100.0)$ & \\
\hline
\end{tabular}

Abbreviations: BID Bis in die (twice daily); IV Intravenous; mg, milligram; MRP medication-related problem; MRSA Methicillin-resistant Staphylococcus aureus; SCAP Severe Community-Acquired Pneumonia; PRN, as needed; PO Per os (by mouth or orally)

${ }^{\text {a }}$ Percentage is calculated taking those with $\geq$ MRP as denominator, $N=323$. Percentage may exceed $100 \%$ due to more than one MRP per patient 


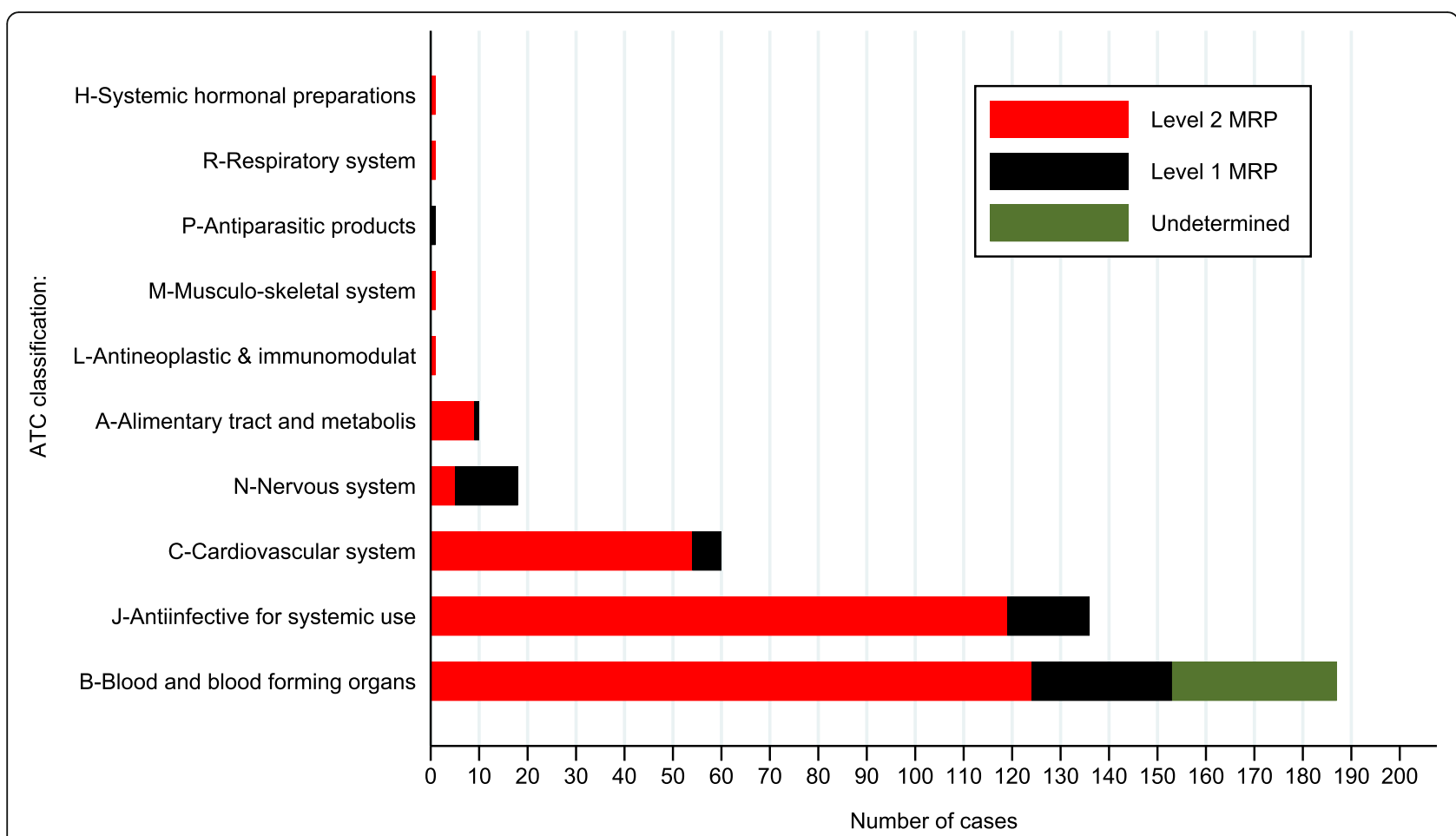

Fig. 1 Overview of the medication groups (by ATC classification system) most commonly involved in MRPs according to severity of the MRP

Another possible reason for the difference in results could be differences in health care systems, the study populations, and disease distribution.

In agreement with the study conducted in Norway [4], 6 out of 10 MRPs in our study concerned the need for additional medication therapy because of untreated illness, mostly in relation to anaemia. In contrast, the study from Australia found that "incomplete medications charted on admission" (28\%) and "incomplete drug order" (15\%) were the two most prevalent MRP categories [3]. The difference may be due to the fact that the Australian study group was able to perform a formal medication reconciliation, which we were not able to do.

Medications acting on the blood and blood-forming organs, anti-infectives for systemic use, cardiovascular drugs, and drugs acting on the nervous system were the medications most commonly involved in MRPs in our study. These findings are relatively similar to prior studies. Antibiotics and iron were the second and third most frequently associated medications in MRPs in the previous Norwegian study [4]. In Australia, most MRPs were related to the alimentary tract and metabolism, and drugs for the nervous system (largely analgesics and antidepressants) [3]. These medication groups may need to be specific focus of the global perspective of MRPs.

Identifying patients with an increased risk of MRPs can be a useful guide for prioritizing tasks in the ward. Our study implies that the focus should be on women with a chronic disease and on women with prior medication use, which is in line with the findings of previous studies [3, 4]. Interestingly, parity was a risk factor for both iron-related MRPs and non-iron-related MRPs, whereas chronic disease and prior medication use were only risk factors for noniron-related MRPs. This may be due to patients with chronic diseases being more likely to use multiple medications, increasing the risk of drug interactions and non-adherence, which in turn increases the risk of MRPs.

Almost half of the moderate to severe (level 2) MRPs (47.8\%) were due to lack of iron supplementation. Another 34 cases had unknown haematocrit due to forgetfulness/lack of time to order standard blood tests or to record patient haematocrit values. Maternal iron deficiency anaemia during pregnancy is associated with multiple adverse outcomes for both mother and infant, including an increased risk of low birth weight, maternal mortality, perinatal mortality, and preterm birth, and is a recognized global problem [28]. This highlights the importance of ensuring an appropriate iron status during pregnancy and after delivery. Giving advice and ensuring that women in need of iron supplements receive it may be the most easily achieved measure to reduce MPRs in maternity care. 


\section{Strengths and limitations}

This study has several strengths, including both its size and the detail of data collected. The use of a standardized system for identifying MRPs, a standardized and systematic chart review at several points during hospitalization, and involvement of a panel of experts in MRP identification are additional important strengths of the present study. Moreover, health care personnel from Ethiopia with knowledge of the healthcare system, local language, culture, and previous research or practice experience performed the data collection.

A major limitation of this study is that our results depended on the accuracy of the chart recording by health professionals. Lack of recording/documentation occurs frequently due to lack of time, and the MRP identification panel agreed to consider it as a documentation problem rather than an MRP for the current study. This will result in an underestimation of the actual number of MRPs. Moreover, JUMC is a referral hospital with a larger proportion of women with pregnancy complications, and possibly with a higher need for medications. As such, the findings will probably not be representative of primary or secondary care services. Finally, as it was difficult to get the patient's full preadmission medication history, no formal medication reconciliation was performed and this could have underestimated the true prevalence of MRPs.

\section{Conclusions}

This study confirms that MRPs are common among women in maternity and gynaecological wards. The most common MRPs were need for additional iron drug therapy, need for additional laboratory test, unnecessary drug therapy, and too low dose of medication. The most important factor associated with MRPs in pregnancy were parity, prior medication use, and chronic illness. Increased adherence to iron supplementation guidelines in inpatient maternity care is urgently needed. Future research should address whether interdisciplinary teams and clinical pharmacy services in the maternity and gynaecology ward can reduce the frequency and consequences of MRPs, and whether this leads to improvements in patient health outcomes.

\section{Supplementary Information}

The online version contains supplementary material available at https://doi. org/10.1186/s12884-020-03433-6.

Additional file 1:. Identification, assessment, classification, and documentation of MRPs and recommendations by the panel of experts

Additional file 2:. Characteristics of the study population according to ward type at JUMC, Ethiopia, from February to June 2017

Additional file 3:. Medications used among hospitalized pregnant women at JUMC, Ethiopia, from February to June 2017
Additional file 4:. Discharge medications prescribed to hospitalized pregnant women at JUMC, Ethiopia, from February to June 2017

Additional file 5:. Types and examples of MRPs identified among hospitalized pregnant women at JUMC, Ethiopia, from February to June 2017

Additional file 6:. Medications involved in MRPs among hospitalized pregnant women at JUMC, Ethiopia, from February to June 2017

\section{Abbreviations}

ANC: Antenatal care; ATC: Anatomical therapeutic chemical classification system; Cl: Confidence interval; HEG: Hyperemesis gravidarum; JUMC: Jimma University medical centre; MMR: Maternal mortality ratio; MRP: Medicationrelated problem; OR: Odds ratio; WHO: World health Organization

\section{Acknowledgements}

The authors thank all of the women who consented to participate in this study. We are also very grateful to the pharmacists, nurses, and physicians who skilfully collected the data and were involved in the expert decisions in MRP identification. We are much indebted to Mr. Bodena Bayissa (clinical pharmacist and lecturer) for his pivotal role in the MRP panel of experts. A special acknowledgement also goes to the Norwegian PhD School in Pharmaceutical Sciences for travel grant assistance for the data collection. Many thanks also to Dr. Ibrahimu Mdala for assisting with the data analysis. Sincere appreciation is extended to the management and staff of Jimma University Medical Centre for making it possible to perform this study.

\section{Authors' contributions}

All authors critically reviewed, contributed important intellectual content to, read, and gave their approval of the final manuscript. SMA and HN conceived the idea for the study and its design. SMA collected, analysed, and interpreted the data and wrote the draft manuscript. YAA and JS did on site supervision of data collection. SMA and $\mathrm{HN}$ revised and finalized the paper.

\section{Funding}

SMA was a PhD student at the University of Oslo during the study. He received a travel grant from Norwegian PhD School in Pharmaceutical Sciences for the data collection. He was also a recipient of a scholarship from the Norwegian Loan Fund (Lånekassen). These institutes were not involved in the design of the study or the collection, analysis, and interpretation of data, or in writing the paper.

\section{Availability of data and materials}

The datasets used during the current study are available from the corresponding author upon reasonable request.

\section{Ethics approval and consent to participate}

The Institutional Review Board, Institute of Health, Jimma University, Ethiopia (date of approval: 17 January 2017; reference number IHRPGC 7206/07), and the Regional Committees for Medical and Health Research Ethics in Norway (date of approval: 17 December 2015; reference number 2015/2135, REK SørØst B) approved the study. All information collected from participants during the study was kept confidential. All individual participants included in the study provided written informed consent.

Consent for publication

Not Applicable.

\section{Competing interests}

The authors confirm that they have no competing interest.

\section{Author details}

${ }^{1}$ Department of Community Medicine and Global Health, Institute of Health and Society, Faculty of Medicine, University of Oslo, Oslo, Norway. ${ }^{2}$ Division of Social and Administrative Pharmacy, School of Pharmacy, Faculty of Health Sciences, Jimma Institute of Health, Jimma University, Jimma, Ethiopia. ${ }^{3}$ Department of Obstetrics and Gynaecology, Faculty of Medical Sciences, Jimma Institute of Health, Jimma University, Jimma, Ethiopia.

${ }^{4}$ Pharmacoepidemiology and Drug Safety Research Group, Department of Pharmacy, Faculty of Mathematics and Natural Sciences, University of Oslo, 
Oslo, Norway. ${ }^{5}$ Department of Child Health and Development, Norwegian Institute of Public Health, Oslo, Norway.

Received: 13 May 2020 Accepted: 17 November 2020

Published online: 26 November 2020

\section{References}

1. Cipolle RJ, Strand LM, Morley PC. Pharmaceutical care practice: the patientcentered approach to medication management services. 3rd ed. New York McGraw-Hill; 2012.

2. PCNEA 2003-2019. PCNE Classification for Drug-Related Problems V9.00. 2019. https://www.pcne.org/upload/files/334_PCNE_classification_V9-0.pdf. Accessed 12 Sep 2019

3. Thompson R, Whennan L, Liang J, Alderman C, Grzeskowiak LE. Investigating the frequency and nature of medication-related problems in the Women's health unit of an Australian tertiary teaching hospital. Ann Pharmacother. 2015:49(7):770-6.

4. Smedberg J, Brathen M, Waka MS, Jacobsen AF, Gjerdalen G, Nordeng $H$ Medication use and drug-related problems among women at maternity wards-a cross-sectional study from two Norwegian hospitals. Eur J Clin Pharmacol. 2016;72(7):849-57.

5. Deepishka P, Gali SD, Arcot M, Durga Prasad TS. Assessment of drug related problems and clinical pharmacist interventions in paediatric department of a tertiary care teaching hospital. Int J Basic Clin Pharmacol. 2018;7(10):19349.

6. Ayalew MB, Megersa TN, Mengistu YT. Drug-related problems in medical wards of Tikur Anbessa specialized hospital, Ethiopia. J Res Pharm Pract. 2015;4(4):216-21.

7. Fernandez-Llamazares CM, Calleja-Hernandez MA, Manrique-Rodriguez S, Perez-Sanz C, Duran-Garcia E, Sanjurjo-Saez M. Prescribing errors intercepted by clinical pharmacists in paediatrics and obstetrics in a tertiary hospital in Spain. Eur J Clin Pharmacol. 2012;68(9):1339-45.

8. Kandil M, Sayyed T, Emarh M, Ellakwa H, Masood A. Medication errors in the obstetrics emergency ward in a low resource setting. J Matern Fetal Neonatal Med. 2012;25(8):1379-82.

9. Little JA, Velazquez MB, Rayburn WF. Reported medication errors in obstetric inpatients in 1 hospital. J Reprod Med. 2003:48(10):818-20.

10. Kebede B, Gedif T, Getachew A. Assessment of drug use among pregnant women in Addis Ababa, Ethiopia. Pharmacoepidemiol Drug Saf. 2009:18(6): 462-8.

11. Beyene KGM, Beza SW. Self-medication practice and associated factors among pregnant women in Addis Ababa, Ethiopia. Trop Med Health. 2018; 46:10.

12. Molla F, Assen A, Abrha S, Masresha B, Gashaw A, Wondimu A, Belete Y, Melkam W. Prescription drug use during pregnancy in southern Tigray region, North Ethiopia. BMC Pregnancy Childbirth. 2017;17:170.

13. Mohammed MA, Ahmed JH, Bushra AW, Aljadhey HS. Medications use among pregnant women in Ethiopia: a cross sectional study. J Appl Pharm Sci. 2013;3(4):116-23.

14. Birarra MK, Heye TB, Shibeshi W. Assessment of drug-related problems in pediatric ward of Zewditu memorial referral hospital, Addis Ababa, Ethiopia. Int J Clin Pharm. 2017;39(5):1039-46.

15. Yimama $M$, Jarso $H$, Desse TA. Determinants of drug-related problems among ambulatory type 2 diabetes patients with hypertension comorbidity in Southwest Ethiopia: a prospective cross sectional study. BMC Res Notes. 2018;11:679.

16. Tigabu BM, Daba D, Habte B. Drug-related problems among medical ward patients in Jimma university specialized hospital, Southwest Ethiopia. J Res Pharm Pract. 2014:3(1):1-5.

17. Niriayo YL, Kumela K, Kassa TD, Angamo MT. Drug therapy problems and contributing factors in the management of heart failure patients in Jimma University specialized hospital, Southwest Ethiopia. PLoS One. 2018;13(10): e0206120.

18. Jimma University. 2018. Jimma University Specialized hospital. http://www. ju.edu.et/jimma-university-specialized-hospital-jush. Accessed 10 Nov 2018

19. Segni $H$, Ayana D, Jarso H. Prevalence of hyperemesis Gravidarum and associated factors among pregnant women at Jimma University medical center, south West Ethiopia: a cross-sectional study. EC Gynaecol. 2016;3(5): 376-87

20. Wolde Z, Segni H, Woldie M. Hypertensive disorders of pregnancy in Jimma university specialized hospital. Ethiop J Health Sci. 2011;21(3):147-54.
21. Woldeyes WS, Asefa D, Muleta G. Incidence and determinants of severe maternal outcome in Jimma University teaching hospital, south-West Ethiopia: a prospective cross-sectional study. BMC Pregnancy Childbirth. 2018;18:255.

22. Gabbe S, Niebyl J, Galan H, Jauniaux E, Landon M, Simpson J, Driscoll D. Obstetrics: Normal and problem pregnancies. 6th ed. Philadelphia: Saunders: 2012.

23. Food, Medicine and Healthcare Administration and Control Authority of Ethiopia. Standard Treatment Guidelines for General Hospital. 3rd ed. Addis Ababa: Food, Medicine and Health Care Administration and Control Authority (FMHACA); 2014.

24. Ward KE, O'Brien BM. Pregnancy and lactation: therapeutic considerations. In: Dipiro JT, Talbert RL, Yee GC, Matzke GR, Wells BG, Posey LM, editors. Pharmacotherapy: a pathophysiologic approach. 9th ed. New York: McGrawHill; 2015. p. 257-300.

25. World Health Organization. Pregnancy, Childbirth, Postpartum and Newborn Care: A Guide for Essential Practice. 2015 https://www.who.int/maternal child_adolescent/documents/imca-essential-practice-guide/en/. Accessed 21 Oct 2019.

26. Cornish PL, Knowles SR, Marchesano R, Tam V, Shadowitz S, Juurlink DN, Etchells EE. Unintended medication discrepancies at the time of hospital admission. Arch Intern Med. 2005:165(4):424-9.

27. World Health Organization: WHO Collaborating Centre for Drug Statistics Methodology, Guidelines for ATC classification and DDD assignment 2016, Oslo, Norway; 2017

28. World Health Organization. Iron Deficiency Anaemia; Assessment, Prevention and Control: A guide for programme managers. 2001. https:// www.who.int/nutrition/publications/en/ida_assessment_prevention_control. pdf. Accessed 5 Dec 2019

\section{Publisher's Note}

Springer Nature remains neutral with regard to jurisdictional claims in published maps and institutional affiliations.
Ready to submit your research? Choose BMC and benefit from:

- fast, convenient online submission

- thorough peer review by experienced researchers in your field

- rapid publication on acceptance

- support for research data, including large and complex data types

- gold Open Access which fosters wider collaboration and increased citations

- maximum visibility for your research: over $100 \mathrm{M}$ website views per year

At BMC, research is always in progress.

Learn more biomedcentral.com/submissions 